\title{
The Influence of Gender on Literacy Education in a Rural Area of Mpumalanga Province of South Africa
}

\author{
Matome M Malale \\ Mpoye L Sentsho \\ University of South Africa Mangosuthu University of Tecnology \\ Email:malalmm@unisa.ac.za, E-mail: sentsho@mut.ac.za
}

Doi:10.5901/mjss.2014.v5n23p1090

\begin{abstract}
In a country such as South Africa whose democracy is relatively new, education for all citizens is of primary concern. Education in general and in particular education of those who had little or no education at all, is high on the priority list. While the government has targeted illiteracy as one of the major issues, others such as gender differentiation in the involvement of learners in adult literacy programs, make the illiteracy situation even more complex, especially in the rural areas where the traditional tenets of the communities are still observed. This study explored the role gender plays in the involvement of learners in adult literacy programs in the rural Bushbuckridge area of Mpumalanga Province, in order to determine the possible implications for literacy programs in rural South Africa. In order to achieve this aim, an interpretive design was applied and qualitative methods of data-collection were utilized. Empirical data was obtained through observations and interviews and processed and analyzed by unitizing and categorizing, resulting in the findings of the research. The results showed that gender does play a role in the involvement of learners in adult literacy programs and that there are implications involved.
\end{abstract}

Keywords: Gender, literacy education, Adult Basic Education and Training (ABET) Mpumalanga Province

\section{Introduction and Background}

The International Literacy Data 2013 state that 774 million adults (of 15 years and above) cannot read and write (UNESCO, 2014 [online]). In South Africa, one of the challenges that the government of democracy inherited from the previous one was the high illiteracy rate, which stood at about 15 million in 1995 (Mathiba, 1995:130). In South Africa 92, $9 \%$ of the citizens can read and write (Pretorius, 2013).

Illiteracy is one of the things that cannot be taken for granted. Problems associated with illiteracy (amongst them poverty), can affect the development of the community. Although literature differ on whether illiteracy cause poverty or vice versa (see The SouthAsialdea Weblog [online], there are other numerous problems associated with illiteracy. The problems include inability to read instructions, inability to write, filling in forms and full participation in the activities of the community.

In order to redress the past historic inadequacies of school education provision, which excluded most people from learning in South Africa, the democratic government included in its Constitution, the Bill of Rights. The Bill of Rights provides a base for the development of education and state that everyone has the right to education including adults, which the state "through reasonable measure, must make progressively available and accessible" (The Constitution of South Africa. Act 108 of 1996).

The Education White Paper 6 of 2001 advanced the Bill of Rights of the Constitution. The vision of the Education White Paper is: "....the development of and inclusive education and training system that will uncover and address barriers to learning and recognise and accommodate the diverse range of learning needs, to build an open, lifelong and high quality education and training system for the $21^{\text {st }}$ Century." The White paper further states that inclusive education should acknowledge and respect differences in learners whether due to age, gender, ethnicity, language, class, disability, HIV or other infectious diseases (Department of Education(DoE), 2001:6).

The stated statistics of $92.9 \%$ of South Africans who can read and write (see above), might be an indication that the illiteracy rate is on the decline (Moeng,2012). Researchers and analysts, however, warn people not to be lulled into believing that this is real as the definition of literacy and the way it is measured is still problematic. Also, as Aitchison and Harley (2006), state, some statistics might not be accurate.

While attempts are made to improve the state of education in general and illiteracy for both men and women in 
South Africa, there are complex issues such as gender differentiation prevailing in the education of adults. This means that in South Africa there are still people who are excluded from learning and whose lives are meaningless as they cannot participate actively in communities they live. The gender differentiation in the involvement of learners in adult education was also observed by the researcher in his engagement as ABET facilitator, ABET Circuit coordinator and ABET coordinator South African National Literacy Initiative (SANLI). The South African Government (online) also reported that $80 \%$ of the Kha Ri Gude Literacy Campaign learners are females.

This study therefore explores the role gender plays in the involvement of learners in adult literacy programs in the rural Bushbuckridge area of Mpumalanga Province, in order to determine the possible implications for literacy programs in rural South Africa.

Bushbuckridge is situated in the low-veld area of the Mpumalanga Province of the Republic of South Africa. It is a rural area with the larger part of the area controlled by chiefs. People in this area speak different African languages with Xitsonga and Sepedi (Northern Sotho) as dominant languages. The area lacks minerals of any economic significance and resultantly there are no big factories to generate employment. It is an agricultural area with most of the people relying on stock and crop farming. The majority of people especially women are vendors and hawkers or working at the plantations, while most of the working men are migrant workers.

\section{Reviewing Literature on Gender, Literacy and Adult Basic Education and Training}

\subsection{Gender, gender stereo-type and education}

The definition of gender cannot be complete without referring to gender stereo-type. The concept of gender stereo-type cannot be complete without showing its impact on education. In defining the three concepts the researcher will also show how they are influence each other.

\subsubsection{Gender}

The term gender is sometimes hard to understand because there is its related term "sex". Gender refers to socially constructed roles, expectations, behaviors, activities, attributes that a given society considers appropriate for men and women. The roles can change over time, place and life stage (Phillips, 2005:1; World Health Organization (WHO), 2014 [online]). Lindsey (2004) adds that gender is learned through socializing process. It determines what is expected, allowed and valued in a woman or a man in a given context. In most societies there are differences and inequalities between women and men in responsibilities assigned, activities undertaken, access to and control over resources as well as decision making opportunities.

Sex refers to the biological and physiological characteristics that define men and women. It is the relatively unchanging nature of being male or female (Phillips, 2005:1, World Health Organization (WHO), 2014 [online]).

\subsubsection{Gender-role stereo-type and education}

Gender-role refers to a set of expectations or behavior that is considered appropriate for a particular gender (Kessler and McKenna, 1978). For example a male is expected to perform male role and behave accordingly (refer 2.1.1). The same applies to a female. The separate roles and behavior associated with each gender may lead to gender role stereo-types and inequalities where one gender is favored, for example in accessing services and opportunities. In most countries the gender-role stereo-type led to the exclusion of women from formal education or women being offered gender-based curriculum (see Blundell, 1992 and Oludipe, 2012). Although there is limited literature that examine gender inequalities in ABET, this sector cannot be an exception.

The issues of gender inequalities were very common before the feminist movements which fought for the eradication of "sexism" and recognition of the rights of women (Blundell, 1992). Now that the pendulum has swung in favor of women, gender is often misunderstood to mean the promotion of women only. In this study the term gender is used to refer to the state of being masculine or feminine. By implication there are two genders, the female and male. The terms male/men and female/women are used interchangeably in literature. This applied to the study as well.

\subsection{Literacy}

The term literacy is defined in a number of ways from different perspectives and may differ according to context or 
countries. In France, the related terms generally used to designate literacy and illiteracy respectfully and from which literacy evolved are alphabétisme (alphabetism) and analphabétisme (analphabetism) (UNESCO, 2006: 148). Literacy is traditionally defined as the individual's ability to read and write (National Institute for Literacy 1998 in Dichaba and Dhlamini, 2013:1). In the context of adult education, it refers to the initial learning of reading and writing for adults who have never been to school. In modern complex society where a person is expected to successfully function at certain levels of society, the term functional literacy is used (Barton, 2006). Complexities of the definition of literacy as well as developments in this field led to the international policy community expanding the definition moving from viewing literacy as "a simple process of acquiring skills, to using these skills in ways that contribute to socio-economic development, to developing the capacity for social awareness and critical reflection as a basis for social awareness and change" (UNESCO, 2006:147).

National Assessment of Adult Literacy (NAAL) defines literacy as both task-based and skills-based. Task-based (conceptual) literacy "is the ability to use printed and written information to function in society, to achieve one's goals, and do develop one's knowledge and potential." The task-based definition focuses on the everyday literacy tasks an adult can and cannot perform. The skills-based (operational) definition refers to literacy as "Successful use of printed material as a product of two classes of skills, namely word-level reading skills and higher level literacy skills" (National Assessment of Adult Literacy (NAAL), 2014 [online]).

In South Africa the term ABET emerged is more often used instead of literacy as it will be explained below (see 2.3).

\subsection{Adult Basic Education and Training (ABET)}

ABET is uniquely a South African concept. In the English-speaking world, ABE (Adult Basic Education) is used. South Africa added the "T" in the policy initiatives of the 1990s, for Training. ABET, which grew out of adult literacy work was adopted rather than literacy, because literacy alone was considered inadequate to support real social transformation.

Literature sources dealing with Adult Basic Education and Training differ on the definition of this concept.

When defined in relation to its place on the National Qualification Authority (NQF), ABET is defined as "basic education for adults at the General Education level of the National Qualification Authority ( that is, NQF level 1 more or less equivalent to the school education from Grade 1 to Grade 9 or Standard (Std) 7" (Aitchison and Harley, 2006: 100). to $\mathrm{DoE}$

For the purpose of this study, the Department of Basic Education (DoE) official definition was adopted. According

"Adult Basic Education and Training is the general conceptual foundation towards lifelong learning and development, comprising of knowledge, skills and attitude required for social, economic and political participation and transformation applicable to a range of contexts. ABET is flexible, developmental and targeted at the specific needs of particular audiences and, ideally, provides access to nationally recognized certificates" ((Adult Basic Education and Training (ABET), 2014 [online].

The above definitions which both refer to adult learning cannot be easily differentiated. They will therefore be used interchangeably in this study.

\section{Research Design and Methods}

The philosophical paradigm (perspective) from which this research was conducted is social or interpretative constructivist. According to Cohen, Manion and Morrison, (2007: 21), the central endeavor of the interpretive paradigm is to understand the subjective world of human experience. With interpretive paradigm efforts are made to retain the integrity of the phenomenon being investigated. Guba and Lincoln (1998:206/207), adds that the interpretive or constructivist perspective seeks to capture and understand reality in its context through the explanations and descriptions of the individuals. In the context of this study the researcher endeavored to understand the participants' experiences in their own environment. Population, i.e. universe (all subjects who possess the attributes in which the researcher is interested) (Brynard and Hanekom, 2006:55), is made up of adult centers in the Bushbuckridge area. The sample (representative of the larger group of population or universe) consists of three centers. The researcher sampled three centers on the basis of their activeness. Interviews were conducted with four groups of 34 participants. The researcher also observed the operations of the centers and took notes.

The groups of participants are depicted in the table below. 
3.1 Representation of the four groups of interviewees at the three literacy centres.

\begin{tabular}{|l|c|c|c|}
\hline Participants & Females & Males & Total \\
\hline Supervisors & 3 & - & 3 \\
\hline Teachers & 3 & - & 3 \\
\hline Learners & 10 & 3 & 13 \\
\hline Dropouts & 3 & 1 & 4 \\
\hline Non-participants & 4 & 7 & 11 \\
\hline
\end{tabular}

The following points need to be noted regarding this diagram and some were noted as observations:

Supervisors: At the three centres selected for actual data-collection, all supervisors were females.

Teachers: At all the three centres that were selected for actual research, the teachers were only females.

Learners: Although the number of female learners exceeds the number of male learners as reflected in the table, the total number of learners in the table does not represent the total number from the centres, only learners who were present on the days interviews took place. Educators, however, indicated that they have more female learners than male learners.

Non-attendants: Only those non-attendants who availed themselves for interviews are represented in the table. A large number of non-attendants were men. Some, however refused to be interviewed as one said: "This government that was voted for with faith, does not provide us with jobs as promised. What is the RDP doing...?"

The process of analyzing data involved identifying the units that are related to each other. Excerpts from interviews with participants served as units which were categorized to form themes. The themes that emerged served as research findings. Since the interviews were conducted in an area of the two dominant African languages (refer 1 above), examples of the excerpts of interviews were also provided in the languages of the respondents. The researcher, however, provided English meaning for the excerpts, in order to make the information accessible to readers of other languages.

\section{Research Findings and Discussions}

Informed by literature, interviews with participants and observations, the following themes emerged and they served as findings for this study:

4.1 Factors that prompt adult learners to attend classes differ in terms of gender, while there are factors that are common to both genders.

This finding, which is one of the main findings of this study indicate that various factors prompt learners to join or not to join adult literacy classes and that the factors differ according to sex. The factors vary from the ability to read, write, sign their names, calculate, speak different languages and obtain jobs. The following are interview excerpts regarding this finding:

Leaner-female: "e-e ebile ke motho wa kapokweni. Ke palelwa ke go saena tšheke". [I am a pensioner. I cannot sign for my cheque].

Non-attendant-male: "Ba ngwadile ke sekgowa gore ga gona mmereko [NO JOB] ... ka ya e le gore ga o tsebe selo." [You discover the sign "NO JOB" (when you are looking for a job). You enter or apply, because you know nothing (you cannot read].

Dropout-female:" Ke kopana le makgowa ... a mpotšiša ... ke palelwa ke go mmotša gore ka mo ke Bush ... ge ke etla sekolong ke a kgona go mmotša." [I meet a white person. He / She asks me for directions, and I am unable to give directions to Bush. If I went to school I shall be able to give directions].

Learners-male: "Go swana le mo dipankeng, akere mo a na le tšheletenyana o tla kgona go bona gore mo ...ba nropie". [At the banks, you are able to react when you have been robbed of your money].

Learner-female: "Le mešomo. Ee gore go na le mešomo ya dikhitšing o kgona go tsena o bereke. Akere ba tla re good morning ... Ba go fa dijo ba re apea. Ga o tsebe ..." [ And jobs. You can be employed to work in the kitchen. The (whites) will say good morning. They give you food to prepare. You are unable to (because you cannot read).

Teacher-female: "Ke gore botšhi bja bona (basadi ba rata go tseba go bala mangwalo a go tšwa go banna ba bona. Ba nyaka go saena dilipi tša ditšhelete tša go tšwa ga banna ba bona." [Most of them (women) want to be able to read letters from their husbands. They want to be able to sign money slips from their husbands].

Learners-female: "......re ile ra šalela kgaleng ka gore re be re diša dikgomo. Bjale e be e le bale ba kgale ba re gatelela ba re ge o le ngwana wa mosetsana e-e-ga o kgone gore o ka tšhuta sekolo ....bjale re bona botlhale bjo 
boswa ....". [We lagged behind because we had to herd cattle. In the past, we were oppressed because girls were not supposed to become educated. Now we experience development].

Learner-female: "... banna akere bona ba ya mmerekong...ba tšhuta. Basadi mo ba ya sekolo ba ya tšhuta bonkwahla, ... ba iša banna fela." [The implication in this excerpt is that education (in African culture) is only for men, as they need it to obtain jobs. Men are the ones who should support their families. Women are prevented from going to school because that would give them the opportunity to engage into sexual relationships with other men].

Reading and writing, together with the desire to find jobs represent strong categories in this pattern. Male as well as female participants indicated their wish to be able to read and write. In this regard, Steinberg and Suttner (1971:79) also state that the ability to read and write has in itself been an important reason for participants to join the literary classes.

Learners and teachers in this study further point out that the ability to read and write can be used by most women to communicate with their husbands at their workplaces. The high employment rate and the fact that working men are migrant labourers who leave their households for jobs in the cities, could be reason for this tendency. jobs.

Participants both men and women indicated that they were motivated to join adult literacy classes in order to get

According to Wolpe (1994:14), men's needs are often particularly associated with employment, while women's needs are associated with domestic labour. Participants in this study indicated that while literacy classes prompted some women to attend, in order to acquire the ability to domestic duties like baking and sewing, and assessing children's school work, they (the women) were also interested in obtaining jobs. Some female participants further indicated that husbands have tendency to leave their wives. Therefore, if they are educated, they do not care, because they can obtain jobs.

In this connection Griesel ( 1987:5) also indicates that the women at Mboza (in Kwazulu-Natal) indicated that they were prompted to join adult literacy classes, in order to obtain jobs, enabling them to provide for their homestead if they were forced to do so. The women further pointed out that sometimes they had marital problems and then they had to provide themselves.

During the interviews adult learners indicated that they were deprived of education when they were young because of their gender. This also happens when some women want to join adult classes. Wives were and are still prevented to attend adult literacy classes by their husbands.

The issue of gender stereo-type which was expressed by different groups of participants, including supervisors, teachers, learners and non- attendants, has also been widely studied in various literature sources. A study done by Hamdan (2005), indicates that education in Saudi Arabia was initially meant for men only. With the introduction of education for women, still education was divided along gender lines. Women received the type of education that would prepare them to be mothers and wives and acceptable jobs such as teaching and nursing. The patriarchal nature of education was aimed at making women subordinates in every field. Horseman (in Hamilton, Barton and Ivanic, 1994: 170) states that girls are frequently made to believe that education prepare them for a role of household work. From childhood a woman is therefore prepared to be a housewife. A woman is quoted by Meer, Skweyiya, Jelobe, Westmore, \& Meer, S. 1991, as having said: "my father would not allow me to go to school. I had to mind cattle" in the past, women were prevented from going to school.

Now the Constitution of South Africa has declared education a right for all. This explains why female learners were in majority at all the centres that the researcher visited.

\subsection{Factors that inhibit men to join adult literacy classes differ according to gender}

Participants were asked why some adults do no attend classes even if there are centres near their homes. They advanced reasons that appeared to be influenced by gender as the following narratives indicate:

Supervisor-female: "...ge o etla ka mo monneng, akere ke hlogo ya lapa, Bjanong o tšeya gore ... bana ba bangwe ba mmona ba re papago mangmang ga a kgone go ngwala le go bala, ba bona okare (maybe) ke go ikiša fase". [When you come to the side of man, he is the head of the family. When small children realize that the father is unable to read, it is a let-down].

Teacher-female: "Banna ba bantšhi ba gona mo ba go se kgone go bala. Bjale ba na le dihlong tša go tla mo sekolong gore ba tšhaba go tsena le basadi ... enngwe gape ke gore banna ba ba ba ba le meberekong, basadi ke bona ba šalago ka mo gae ba kgone go ya sekolong" [There are many illiterate men in the community. They are ashamed to attend classes together with women. Also, men are at work, while women remain at home and have the opportunity to attend classes]. 
Learner-male: "... mo ga rena ...banna gore ba sa be gona, ke go rata madila" [ Men do not attend our school because they prefer drinking liquor].

Another inhibitor that emerged pertains to instability in families and it affects mostly women. Female participants who were asked why they did not attend classes for adults responded as follows:

Non-attendant-female: "Lexi xi hluphaku I kuri mina kahlekahle, ndzi munhu langa na vana lava tshamaka ekaya, se mina na bava wa vana hi hambanile. Se andzi koti kuya exikolweni hikuva vana va dyondzisiwa hi mina xikolo ..." [I am a house wife who has children to bring up. I cannot go to school because I divorced the father of my children].

Non-attendant-female: "...nka se fo hlwa ke dulele papa ke re kgwedi ye o a boya a sa boye ...ga a bereke thina ...le gona ga a boye tsona. Ka ba ka bona gore se kaone ke gore ke nyake matogo". [l cannot just wait for my husband to come home, as he does not come often (to bring money for food). He works far. He only comes home after a long time. I thought it wise to look for job, in order to support the children and can therefore not attend adult literacy classes]. Literacy supervisors indicated that female learners are in the majority at adult literacy centres because male being heads of families are ashamed to attend classes, together with women. Also, being heads of families, children will despise them. According to study on adult literacy in Kenya, men were not favour of joining adult literacy classes together with women because women performed better, and they found this humiliating (International Institute for Adult Literacy methods, 1971: 76; Meer, et al., 1991:96).

The issue of males and alcoholism emerged as strong finding regarding gender-issues. During the research's interviews, teachers advised the researcher to visit shebeens and liquor stores, as the researcher would find most of the male non-attendants

The researcher discovered the problem of alcoholism to be closely related to the socio-economic situation in this area. As mentioned previously (see 1), the area in which the study took place, is impoverished, and it lacks minerals of any economic significance, that could lead to the establishment of factories to generate employment. As a result, the majority of unemployment men resort to drinking liquor. Some of these men do not regard education as having any value.

The issue of alcoholism is supported by literature. In her studies within the Mboza community of Kwazulu-Natala, Griesel (1987:5) found that because men are not able to make a living of the land, they just wake up in the mornings and go to the "joint" (a shebeen where illegal liquor is sold) to drink, to "dim" their minds and forget about their sorrows.

Literacy teachers indicated that one of the reasons why females dominated in classes was that women stay at home men were at work. Probably because of lack of electricity, lessons are conducted during the day, when the majority of men are at work. French (in Hutton, 1992:51) also points out that domestic women workers who stay at home have a greater opportunity to become literate than men who are working in unskilled jobs, where literacy skills are not required.

The issue of unstable families was raised by some participants affected mostly women. There were women who were divorced and could therefore not attend adult classes. They were forced to go and work to support their children. It was indicated above (see 1) that men in the area worked as migrant workers. They went to the cities never to come back. Wives were forced to look for jobs to feed their children and could therefore not attend classes. Studies indicate that in countries where divorce rates are extremely low, wage work for women is of less importance. In countries where divorce rates are high, women labour force participation is high (Braunstein, 2008:3).

The issue of jobs referred to previously as a factor attracting adult learners to join literacy centres, can on the other side inhibit learners especially female learners to attend. They (female learners) would blame lack of opportunities of paid work for females. In this regard, Favish (as quoted in Graven, Favish, Romm, Mckay, Sarakinsky, Cooper \& Northedge, 1991:43) quotes Radebe as having said: "....because of lack of opportunities for paid work, the women did not see why they should work hard to learn to read and write."

\subsection{Performance of adult learners differ according to gender}

The responses in this finding are expressed by literacy teachers. The finding involves the performance of adult learners and their interests.

The following are some of the interview excerpts regarding this finding:

Teacher-female: "Banna ba ba phala ...ba le active go phala basadi....kudu ge o etla mo go English. ...basadi bona ba bontšha ba rata (disubjects) ka moka" [Male learners perform better and are more active than female learners. Male learners like English. Female learners seem to enjoy all the subjects].

Teachers' observations regarding the performance of male and female leaners are in agreement with literature, while also contradicting some of the literature sources the researcher has studied. The issue of gender and academic achievement has been debated in various literature sources. Studies show that males' scholastic achievement is higher 
than females (Education.com 2014 [on line], while others show the contrary. Further studies show that females are good in languages while males are good in sciences. Yet other studies (Liver, Davis-Kean and Eccles, 2002; Oludipe, 2012) contend that there is no gender difference as both sexes do equally in sciences. If there was a difference, it is gradually declining. Most of the differences were caused by biases and misconceptions especially about women and science, which result from gender stereo-type and females lack of exposure to field of science.

Realizing the inconsistency in the whole issue of performance, the researcher tends to regard the various observations as mere perceptions by individuals, and not based upon facts. In addition, many other factors determine the performance of learners. Studies by Blundell (1992) show that the psychological women's lack of equality, i.e. women do not get what men do out of education, make them (women) conditioned mentally not to get what men get. Other factors can include the idea that the teachers are socialized into thinking that males should perform better than females. The context in which this study was done, i.e. a rural area where a system of patriarchy still prevails, it cannot be concluded that one sex definitely performs better than the other. Female learners may prefer living according to the traditional female conduct in the presence of males being submissive and silent, or decide to be passive or regard competition with men as abnormal. On the other hand, men who come from families where they are still regarded as superiors may regard silence or passivity as failure in the presence of female leaners, and also an embarrassment in the presence of female teachers.

\section{Implications and Recommendations}

Taking into consideration the context of this study, theory from literature, and data collected through observation and interviews, it can be deduced that gender does play a role in the involvement of learners in adult literacy programmes in the rural Mapulaneng area of the Mpumalanga Province. The following are therefore implications for adult literacy programme provision and the accompanying recommendations:

\subsection{Flexible programme delivery and resourcing of centres for adult learners}

Dominance of female adult learners is ascribed to a variety of reasons as indicated above. The main reason being that while they were prevented by culture from attending schools in the past, women are becoming aware of their rights because of the new government (of non-sexist democracy) that urges women to learn and acquire important life skills. If the dominance persist it would imply the lopsided provision of education which according to the Constitution of South Africa, is meant for all. Also, if lessons are conducted during the day, when the majority of potential learners (especially men) are at work it will imply that the majority of men will continue to be excluded from learning.

An obvious option will be to offer lessons during the evenings, when all workers are back from work and can attend classes. This will, however, imply that electricity be installed, as schools lack this important facility. Alternatively, the "double-sessions system" could be introduced. This will enable those who are available during the day to attend classes during the day, while those who are working during the day, can attend during the evening. A flexible programme delivery system similar to that of Kha Ri Gude National Mass Literacy Campaign, can also be an alternative. Kha Ri Gude (let us learn) offers lessons to adult learners everywhere any time and days convenient to the learners. Lessons are held even during the weekends.

\subsection{Holistic approach to programme delivery}

Some needs appear to be specific to female learners. These needs are associated with duties, traditionally assigned to women in the rural areas, e.g. needs include the ability to cook, to assess children's school work and most important, to communicate with their husbands at their workplaces. No needs appear to be specific to males, except that their needs are more job-orientated. The implication here again is that learning will be exclusive as the adult centre will not be offering what some would like to learn.

A holistic approach will be recommended. A holistic approach would mean that programmes should not offer literacy per se (although literacy represents the main content of adult literacy education). Rather than teaching literacy only, other needs of the learners should also be addressed. The programmes should not only deal with individual needs, but aim to address the needs that learners express (male and female) as well as the needs they might not be aware that they have. This can help, curb non-attendance rates, as well as dropout rates as adult learners have the tendency to drop out if their needs are not addressed.

A holistic approach also means that the programme content should be integrated, in the sense that instead of 
being taught reading and writing only, adult learners in this area should be taught skills of establishing and maintaining agricultural projects like vegetable plots, in order to create jobs while generating income. This can help address the immediate problem of sufficient job opportunities. One can further add that, while most of the inhabitant are hawkers and vendors, they need skills to manage their small businesses or so- called "spaza" (tuckshops).

A holistic approach would also address the issues of alcoholism and patriarchy which were said to be affecting attendance of male learners negatively (see 4.1, 4.2 and 4.3). A holistic approach, in the sense of including or emphasizing in the content "the value of education and the dangers associated with alcoholism" and patriarchy which compromise gender equity. Although the issue of alcoholism can be closely associated to the socio-economic conditions in the area, some inhabitants might not regard education as being valuable. As a traditional community, some might believe that their forefathers could survive without education while also enjoying liquor. A system of patriarchy is still deeply rooted in some African cultures. Including issues of patriarchy as part of curriculum content may improve gender sensitivity.

\subsection{Review, enforcement of legislation and education on gender}

The promotion of the patriarchal system will imply the continuous impact on adult attendance of classes. Some males will not attend adult education classes and may resultantly not allow their wives to attend as they would be clever than them. Until recently in African communities, the system of matriarchy has been gaining ground. However, there are still those women and men who are educated and can understand issues related to the freedom of individuals, seem to fall back into the old patriarchy system.

This problem could be addressed by the government through legislation. The government has, however, seemingly realized how deeply rooted the system of patriarchy is in African culture and that favouring Western social practices may not work. Legislation passed seems not to be addressing the issues of gender, role-division, and patriarchy successfully. While advocating non-sexist democracy, the legislation recognizes some traditional practices, such as the customary marriage system and traditional leadership, both of which observe the system of patriarchy.

As long as the system of patriarchy still exists in African communities, non-attendants of adult literacy classes by males will in the researcher's opinion, be affected. Recognition of the customary marriage system and traditional leadership as enshrined in the Constitution needs to be reviewed. If these issues are not removed from the constitution, they should be amended and enforced in such a way that women do not remain inferior positions. These actions might change perception about the role of women, although it will not happen overnight, as these issues are so deeply rooted in African culture.

Changing the curriculum of ABET may not be a simple task. Moreover, the curriculum is prescribed. The Department can conduct trainings with educators on current legislations on gender issues especially as they impact on the lives of adult learners in general and in particular their learning. The educators will in turn impart the knowledge to the learners.

\section{Conclusion}

The aim of this study was to explore the role gender plays in the involvement of learners in adult literacy programs in the rural Bushbuckridge area of Mpumalanga Province, in order to determine the possible implications for literacy programs in rural South Africa. The research findings depict that gender does play a role and that there are implications in the involvement of learners in adult literacy programs. Although the findings and implications are localized, i.e. applying to the Bushbuckridge area, it is possible that other rural communities in the Mpumalanga Province or outside the boarders of the province might experience similar problems. Therefore, these research findings and implications might also be applicable to other rural communities in the Republic of South Africa.

\section{References}

Adult Basic Education and Training (ABET) in South Africa. Supporting adult learning in South Africa. About ABET. http://www.abet.co .za/about.html (Accessed 18/07/2014).

Aitchison, J. J. W \& Harley, A. (2006). South African illiteracy statistics and the case of the magically growing number of literacy and ABET learners. Journal of Education. No. 39, pp.89- 112.

Barton, D. (2006). Literacy: Introduction to the Ecology of Written Language. $2^{\text {nd }}$ ed. Oxford: WileyBlackwell.

Blundell, S. (1992). Gender and the curriculum of adult education. International Journal of Lifelong Education. 11:3 199-216. 
Braunstein,E. (2008). Women's employment, empowerment and globalization: An economic perspective. Paper. New York-U.N.Division for the Advancement of women, Department of Economic and Social Affairs.

Brynard, P.A \& Hanekom, S. Y. (2006). Introduction to research in management related fields. $2^{\text {nd }}$ ed. Pretoria: Van Schaik.

Cohen, L; Manion, L. \& Morrison, K. (2007). Research methods in education. 6th ed. London: Routledge.

Department of Education (DoE). (2001). Education White Paper 6. Special needs education. Pretoria: DoE.

Education.com. Gender and Academic Achievement. http://www.education.com/reference.artfield gender-academic-achievement. (Accessed 21/07/2014).

French, E. (1992): Adult Literacy in South Africa: Post to present. (In Hutton, B. (ed). (1992): Adult Basic Education in South Africa. Literacy, English as a second language, and numeracy. Cape Town: Oxford University Press, pp. 48 - 85).

Graven, M; Favish, J;Romm, N;McKay,V; Sarakinsky, M; Copper, L 7 Northedge, A. (1995)Practitioner Training Course in Adult Basic Education Nad Training. Mnaging projects. Nit for Adult Basic Education and Training. Pretoria: UNISA.

Griesel, H. (1987). Sibambene. The voices of women at Mboza. Johannesburg: Ravan Press.

Guba, E. G. \& Lincoln, Y. S. (1998). Competing paradigms in qualitative research. (In M. K. Denzin Y. S. Lincoln (1998) (eds). The landscape of qualitative research: Theories and issues (pp.95-220). London: SAGE Publications.

Hamdan, A. (2005). Women and education in Saudi Arabia: Challenges and achievements. International Education Journal, 2005, 6(1), $42-64$.

Horseman, I. (1994). The problem of illiteracy and the promise of literacy. (In Hamilton, M. Barton, D \& Ivanic, R. eds. (1994): Worlds of literacy. Toronto: Ontario Institute for studies in Education, pp. 17 - 181).

International Institute for Adult Literacy methods. (1971): Literacy Projects. Final report on the replies received to the institute's questionnaire, 1969-1970. November,1971.

Lindsey, L. L. (2005). Gender Roles: A Sociological Perspective. London: Prentice Hall.

Linver, M.R; Davis-Kean, P.E \& Eccles, J.S (2002) April. Influences of Gender on Academic Achievement. Presented at the biennial meetings of the Society for Research on adolescence. New Orleans, L.A.

Mathiba, T. (1995). ABC and RDP. City Press, 11 June, 1995.

Meer, F; Skweyiya, S.; Jelobe, S; Westmore, J. V \& Meer, S. (1991). Black-women workers. A study of patriarchy, race and women production workers in South Africa. 2nd edition. Durban: Madiba Publishers.

Moeng, K. (2012) October 15. Illiteracy on decline in South Africa. Sowetan.

National Assessment of Adult Literacy (NAAL)-Definition of literacy. National Centre for Education Statistics. http://nces.ed.gov/naal/frdefintion.asp. (Accessed 18/07/2014).

National Institute for Literacy (1998) (In Dichaba, M. M. \& Dhlamini, J. P. The value of critical pedagogy in mass education for reducing illiteracy in South Africa. Kha Ri Gude current realities and prospects. Mediterranean Journal of Social Sciences. Vol.4 No.3 September 2013.

Oludipe, D.I. (2012). Gender differences in Nigerian Junior Secondary School students' Academic Achievement in Basic Science. Journal of Educational and Social Sciences.

Philips, S. P. (2005). Defining and measuring gender: A social determinant of health whose time has come. International Journal for Equity in Health 2005; 4:11.

Pretorius, S. (2013). August 29. South Africa's level of literacy. Citizen.

Steinberg, C \& Suttner, Meds. (1991). Never too old to learn. Toward formulating policy in Adult Basic Education in a post-apartheid South Africa Johannesburg: Learn and teach publication.

The Constitution of the Republic of South Africa. Act 108 of 1996.

The SouthAsianldea Weblog. Is illiteracy the cause of poverty? http://the southasiaidea.wordpress.com (Accessed 01/08/2014).

South Africa Government. Kha Ri Gude Literacy Campaign. http://www.gov.za. (Accessed 01/08/2014

UNESCO Institute for Statistics. International Literacy Data. Literacy rates are rising, but women and girls continue to lag behind. (http://www.uis.unesco.ora/literacy (Accesses 26/07/2014

UNESCO. Education for all Global Monitoring Report, 2006.

Wolpe, A. (1994). Adult Education and women's needs. A study of some community organizations in Western Cape. University of Western Cape: CACE.

World Health Organisation. Gender, women and wealth. What do we mean by "sex" and "gender"? http://www.who.int/gender/what is gender/en/ (Accessed 2014/07/18). 